\title{
Career Regret Among Physician Assistants: A Comparative Survey of Primary and Specialty Care Careers
}

\author{
Talia Sierra \\ Idaho State University, siertali@isu.edu \\ Jennifer Forbes \\ University of Utah, forbjenn@isu.edu \\ Michael Nelson \\ Rocky Mountain University of Health Professions, mnelson@rmuohp.edu
}

Follow this and additional works at: https://nsuworks.nova.edu/ijahsp

Part of the Family Medicine Commons, Other Medicine and Health Sciences Commons, and the Primary Care Commons

\section{Recommended Citation}

Sierra T, Forbes J, Nelson M. Career Regret Among Physician Assistants: A Comparative Survey of Primary and Specialty Care Careers. The Internet Journal of Allied Health Sciences and Practice. 2019 Jan 01;17(1), Article 10.

This Manuscript is brought to you for free and open access by the College of Health Care Sciences at NSUWorks. It has been accepted for inclusion in Internet Journal of Allied Health Sciences and Practice by an authorized editor of NSUWorks. For more information, please contact nsuworks@nova.edu. 


\title{
Career Regret Among Physician Assistants: A Comparative Survey of Primary and Specialty Care Careers
}

\begin{abstract}
Purpose: This study investigated if career regret varies among physician assistants (PAs) practicing in primary and specialty care fields. This information may assist practicing and aspiring physician assistants when selecting or changing their career path.

Methods: A survey was emailed to 5,000 primary and specialty care physician assistants. Items indicating career regret were compared between primary and specialty care groups.

Results: Eight hundred and thrity-four (16.7\%) completed surveys were received back. Career regret is similar between primary and specialty care physician assistants, with low reports from both groups. No statistical significance was found between primary care and specialty care groups with regards to career regret or student loan debt. The primary care group noted a less sustainable work/ life balance and higher perceived burnout. Specialty care physician assistants reported higher annual gross income. Regret and disappointment correlated highly with burnout.

Conclusions: Physician assistants and prospective physician assistants should carefully consider their career path as regret and disappointment correlated highly with burnout.
\end{abstract}

\section{Author Bio(s)}

Talia M. Sierra, MPAS, PA-C, Assistant Professor with the Department of Physician Assistant Studies at Idaho State University. She is also a licensed physician assistant in the state of Idaho.

Jennifer Forbes, MHS, PA-C, Assistant Professor in the Division of Physician Assistant Studies at the University of Utah School of Medicine. She is also a licensed physician assistant in the state of Utah.

Michael L. Nelson, DHSc., MPAS, PA-C, Associate Program Director and Assistant Professor with the Department of Physician Assistant Studies at Rocky Mountain University of Health Professions in Provo, UT.

\section{Acknowledgements}

The Idaho State University Physician Assistant Studies Faculty Grant was awarded to the authors in the amount of $\$ 500$ for the purposes of purchasing the e-mail rental agreement from AAPA and to purchase participation incentives of four $\$ 50$ amazon gift cards to award to four random survey participants. Prior to data collection, the survey and research proposal were reviewed by our Institutional Review Board and determined to be exempt. 


\title{
1IVAHSP \\ The Internet Journal of Allied Health Sciences and Practice \\ Dedicated to allied health professional practice and education \\ Vol. 17 No. 2 ISSN 1540-580X
}

\section{Career Regret Among Physician Assistants: A Comparative Survey of Primary and Specialty Care Careers}

\author{
Talia Sierra ${ }^{1}$ \\ Jennifer Forbes ${ }^{2}$ \\ Michael Nelson ${ }^{3}$ \\ 1. Idaho State University \\ 2. University of Utah \\ 3. Rocky Mountain University of Health Professions \\ United States
}

\begin{abstract}
Purpose: The purpose of this study was to determine possible factors (eg type of practice) affecting career regret among physician assistants (PAs). This information may assist practicing and aspiring physician assistants when selecting or changing their career path. Methods: A survey was emailed to 5,000 primary and specialty care physician assistants. Items indicating career regret were compared between primary and specialty care groups. Results: Eight hundred and thirty-four (16.7\%) completed surveys were received. Career regret is similar between primary and specialty care physician assistants, with low reports from both groups. No statistical significance was found between primary care and specialty care groups with regard to career regret or student loan debt. The primary care group noted a less sustainable work/life balance and higher perceived burnout. Specialty care physician assistants reported higher annual gross income. Regret and disappointment correlated highly with burnout. Conclusions: Physician assistants and prospective physician assistants should carefully consider their career path as regret and disappointment correlated highly with burnout.
\end{abstract}

Keywords: PA career regret, primary care, specialty care, PA burnout, physician assistant

\section{INTRODUCTION}

Burnout and job satisfaction among physician assistants (PAs) has been extensively studied; however, research evaluating career regret among PAs has not been conducted. ${ }^{1-5}$ Although many reports on career satisfaction have been done, none have compared career regret between primary care and specialty care PAs. ${ }^{1-5}$ This information is important to consider when choosing or changing a career path, particularly with an evolving medical environment, increased patient demands, and industry shortages. ${ }^{6}$

Although research is lacking in regard to PA career regret, a study on career regret among physicians showed burnout and regret decrease after residency. ${ }^{4} \mathrm{~A}$ review article by Hoff revealed high levels of satisfaction among physicians, but specifically noted a need to evaluate satisfaction in a new way because of the changing work environment. ${ }^{7}$ Many factors may play a role in career regret including salary and student loan debt. A study by Phillips attributed the shortage of family practice clinicians to student debt citing that pay is higher in specialties, making the selection of a family practice specialty a less practical career selection. ${ }^{8}$ 
PAs have the unique ability to change specialties, and many may be considering a career change from a primary care field to a specialty care field or vice versa. Additionally, PA students may ask themselves which field may best suit their lifestyle as they look at beginning their careers. Advice in these areas can be difficult to offer because of limited availability of comparative studies and the needs and desires of each individual.

A PA may be satisfied with his or her choice of occupation, but if given the chance to choose again, may choose to pursue a different career path. It is possible that PA career regret may be present even though the PA reports career satisfaction. The purpose of this study was to determine if career regret differs among PAs practicing in primary and specialty care fields. Additional factors that may play a role in determining career regret were also evaluated in this study. This information may assist PAs when selecting or changing their area of medicine and help those considering a career as a PA determine if the profession is the right fit for them.

\section{METHODS}

A 24-item survey was developed for the present study that collected demographic data, area of specialty, and information about the participants' career as a PA. This included asking about the PAs perceived level of burnout, sustainability of work/ life balance, control of schedule, and satisfaction regarding PA career. Three items were used to measure regret and are shown in Table 1. Prior to data collection, the survey and research proposal were reviewed by our Institutional Review Board and determined to be exempt. Participation in the survey implied consent.

Table 1. Regret items

\begin{tabular}{|l|l|}
\hline \multicolumn{1}{|c|}{ Item } & \multicolumn{1}{c|}{ Selection options } \\
\hline $\begin{array}{l}\text { 16. If you were advising a person who is considering a career } \\
\text { as a PA, how would you advise them? }\end{array}$ & $\begin{array}{l}\text { Pursue PA school } \\
\text { Go to medical school } \\
\text { Choose a different healthcare profession } \\
\text { Enter a different field altogether }\end{array}$ \\
\hline $\begin{array}{l}\text { 21. Do you feel your profession has been worth the sacrifices } \\
\text { that you made in order to become a PA? }\end{array}$ & $\begin{array}{l}\text { Yes } \\
\text { No }\end{array}$ \\
\hline $\begin{array}{l}\text { 22. If you could choose again, would you choose to become } \\
\text { a PA or choose a different career path? }\end{array}$ & $\begin{array}{l}\text { Attend PA school again } \\
\text { Choose a different career path }\end{array}$ \\
\hline
\end{tabular}

An email rental agreement was established with the American Academy of PAs (AAPA) for use of 5,000 email addresses of PAs who are currently registered members of the association. The list contained 2,500 primary care and 2,500 specialty care PA email addresses. The primary care group consisted of specialties listed by the Center for Medicare and Medicaid Services as primary care. ${ }^{9}$ This included family practice and internal medicine. Geriatrics and pediatrics were requested by the authors, but email addresses in these categories were unable to be provided by AAPA. Our survey asked respondents to indicate which area of medicine they practice in; therefore, respondents working in geriatric and pediatric fields were able to indicate such on the survey and were appropriately categorized into the primary care field based on their survey response. All other areas of practice were placed in the specialty care group with approximately 150 email addresses selected from each specialty available with the exception of those that had less than 150 email addresses available from AAPA. See Table 2 for the email distribution among specialties as designated by AAPA. Pediatric and geriatric specialties are omitted from the table as AAPA was unable to provide these specialties. Invitations to participate were sent via Qualtrics online software.

Table 2. Specialty distribution as designated by AAPA for invitation to participate in survey.

\begin{tabular}{|l|l|l|c|}
\hline \multicolumn{1}{|c|}{ Primary Care } & Number of Invitations & \multicolumn{1}{c|}{ Specialty Care } & Number of Invitations \\
\hline Family Medicine & 1250 & Allergy and Immunology & 116 \\
\hline Internal Medicine & 1250 & Anesthesiology & 71 \\
\hline & & Cardiology & 150 \\
\hline & & Dermatology & 172 \\
\hline & & Emergency Medicine & 150 \\
\hline & & General Surgery & 150 \\
\hline & & Hematology/ Oncology & 150 \\
\hline & & Hospital Medicine & 150 \\
\hline
\end{tabular}

(C) The Internet Journal of Allied Health Sciences and Practice, 2019 


\begin{tabular}{|l|l|l|c|}
\hline Primary Care & Number of Invitations & Specialty Care & Number of Invitations \\
\hline & & Neurology & 150 \\
\hline & & Obstetrics and Gynecology & 150 \\
\hline & & Occupational Medicine & 150 \\
\hline & & Orthopedic Surgery & 150 \\
\hline & & Pain Management & 150 \\
\hline & & Psychiatry & 150 \\
\hline & & Public Health & 41 \\
\hline & & Radiology & 150 \\
\hline & & Urology & 150 \\
\hline Total & & Surgery & 150 \\
\hline
\end{tabular}

The completed surveys were categorized into primary care and specialty care groups in the same manner as described above based on the current area of medicine participants reported in the survey.

Independent samples $t$ tests were utilized to determine significance on Likert-type scale questions between primary and specialty care groups. This included items looking at degree of control over schedules, perceived levels of burnout, satisfaction with career choice, and the degree to which respondents have a sustainable work-life balance. Control over schedules and perceived levels of burnout were scored on a 1-5 scale with career satisfaction and work-life balance reverse scored so lower scores correspond to less control, burnout, career satisfaction and sustainability of work/ life balance.

Chi square analysis was used to determine significance on the three questions indicating regret and non-Likert-type scales which included number of hours worked per week, annual salary, amount of student loan debt, number of jobs held, number of children, and relationship status.

\section{Determining Regret}

Answer selections for the three regret items were categorized into responses that indicated regret and answers that did not indicate regret. When asked how to advise someone considering a career as a PA, any selection other than "pursue PA school" indicated regret. The three other selections were collapsed into one category as they did not indicate regret. When asked if the profession has been worth the sacrifices made in order to become a PA, responses of "no" were used as an indicator of regret. A selection of "choose a different career" when asked if respondents would choose to become a PA again was also used as an indicator of regret.

\section{Satisfaction with Decision}

A validated, six-item Satisfaction with Decision Scale was included in the survey regarding the decision to become a PA. ${ }^{10}$ All items were scored in the same direction with higher scores indicating greater dissatisfaction. ${ }^{10}$ Pearson correlation coefficient was used to determine correlations between this validated scale, the three regret items in the survey, and burnout.

\section{Decision Regret Scale}

Similarly, a validated, five-item Decision Regret Scale was included in the survey and adapted to reflect the decision to become a PA. ${ }^{11}$ Two items were reverse scored and calculated as a mean with higher scores indicating more regret. ${ }^{11}$ Pearson correlation coefficient was used between this validated scale, the three regret items, and burnout. For all items, a $p$ value equal to or less than .05 was used to determine significance, indicating a $95 \%$ confidence interval.

\section{RESULTS}

Of the 5,000 surveys emailed, 834 (16.7\%) completed surveys. The physician assistant participants resided in all 50 states. The specialty care group included 501 responses, while the primary care group included 333 responses. Respondents were predominantly Caucasian $(n=704,85 \%)$, female $(n=615,74.4 \%)$, and married $(n=617,74.7 \%)$. A total of $18.6 \%(n=154)$ were single, $5.7 \%(n=47)$ divorced and $1 \%$ widowed $(n=8)$. Other ethnicities reported were Asian $(n=30,3.6 \%)$, African American $(n$ $=23,2.8 \%$ ), and Hispanic, Latino or Spanish origin $(n=21,2.5 \%)$. All others categories contained less than $1 \%$ of respondents while $3.5 \%$ declined to answer. Many respondents had no children $(n=331,40 \%), 13.1 \%(n=108)$ had one, $29.8 \%(n=246)$ had two, $11.9 \%(n=98)$ had three, $4 \%(n=33)$ had four and 1.3\% $(n=11)$ had five or more children. Most respondents were working one $(n=655,79.11 \%)$ or two $(n=116,14 \%)$ positions as a PA. Just over $33 \%(n=271)$ had been in practice for more than 15 years while $18.19 \%(n=149)$ of respondents selected 10 to 15 years and another $18.19 \%(n=149)$ selecting 5 to 10 years. An 
additional $17.83 \%(n=146)$ selected 2 to 5 years. Respondents with 1 to 2 years of experience made up $7.45 \%(n=61)$ of respondents and $5.25 \%(n=43)$ had less than 1 year of experience. Table 3 demonstrates a side by side comparison of this demographic information between groups.

Table 3. Demographic Data by Primary and Specialty Care Groups

\begin{tabular}{|c|c|c|c|c|c|c|c|}
\hline & All respondents & $N$ & Primary Care & $n$ & Specialty Care & $n$ & $\begin{array}{l}p- \\
\text { value }\end{array}$ \\
\hline Age (average years) & 42.36 & 631 & 42.79 & 259 & 42.06 & 372 & .460 \\
\hline Ethnicity & $100 \%$ & 810 & $100 \%$ & 332 & $100 \%$ & 478 & .728 \\
\hline White American & $84.9 \%$ & 688 & $87.3 \%$ & 290 & $83.3 \%$ & 398 & \\
\hline Asian or Asian American & $3.7 \%$ & 30 & $2.4 \%$ & 8 & $4.6 \%$ & 22 & \\
\hline Black or African American & $2.7 \%$ & 22 & $2.1 \%$ & 7 & $3.1 \%$ & 15 & \\
\hline $\begin{array}{l}\text { Hispanic, Latino or Spanish } \\
\text { origin }\end{array}$ & $2.6 \%$ & 21 & $3.0 \%$ & 10 & $2.3 \%$ & 11 & \\
\hline Middle Eastern or North African & $0.7 \%$ & 6 & $0.6 \%$ & 2 & $0.8 \%$ & 4 & \\
\hline $\begin{array}{l}\text { Native Hawaiian or Other } \\
\text { Pacific Islander }\end{array}$ & $0.4 \%$ & 3 & $0.3 \%$ & 1 & $0.4 \%$ & 2 & \\
\hline $\begin{array}{l}\text { American Indian or Alaskan } \\
\text { Native }\end{array}$ & $0.2 \%$ & 2 & $0.3 \%$ & 1 & $0.2 \%$ & 1 & \\
\hline Other race or ethnicity & $1.2 \%$ & 10 & $1.2 \%$ & 4 & $1.3 \%$ & 6 & \\
\hline Prefer not to answer & $3.5 \%$ & 28 & $2.7 \%$ & 9 & $4.0 \%$ & 19 & \\
\hline Relationship & $100 \%$ & 808 & $41.0 \%$ & 331 & $59.0 \%$ & 477 & .148 \\
\hline Married & $74.4 \%$ & 601 & $77.0 \%$ & 255 & $72.5 \%$ & 346 & \\
\hline Single & $18.8 \%$ & 152 & $16.3 \%$ & 154 & $20.5 \%$ & 98 & \\
\hline Divorced & $5.8 \%$ & 47 & $6.3 \%$ & 21 & $5.5 \%$ & 26 & \\
\hline Widowed & $1.0 \%$ & 8 & $0.3 \%$ & 1 & $1.5 \%$ & 7 & \\
\hline Gender & $100 \%$ & 809 & $40.9 \%$ & 331 & $59.1 \%$ & 478 & .447 \\
\hline Male & $25.2 \%$ & 204 & $23.0 \%$ & 76 & $26.8 \%$ & 128 & \\
\hline Female & $74.4 \%$ & 602 & $76.7 \%$ & 254 & $72.8 \%$ & 348 & \\
\hline Prefer not to answer & $0.4 \%$ & 3 & $0.3 \%$ & 1 & $0.4 \%$ & 2 & \\
\hline Number of Children & $100 \%$ & 809 & $100 \%$ & 331 & $100 \%$ & 478 & .692 \\
\hline 0 & $40.0 \%$ & 324 & $39.0 \%$ & 129 & $40.8 \%$ & 195 & \\
\hline 1 & $13.3 \%$ & 108 & $13.9 \%$ & 46 & $13.0 \%$ & 62 & \\
\hline 2 & $29.7 \%$ & 240 & $27.8 \%$ & 92 & $31.0 \%$ & 148 & \\
\hline 3 & $11.6 \%$ & 94 & $13.3 \%$ & 44 & $10.5 \%$ & 50 & \\
\hline 4 & $4.0 \%$ & 32 & $4.5 \%$ & 15 & $3.6 \%$ & 17 & \\
\hline 5 or more & $1.4 \%$ & 11 & $1.5 \%$ & 5 & $1.6 \%$ & 6 & \\
\hline $\begin{array}{l}\text { Number of jobs currently } \\
\text { working as a PA }\end{array}$ & $100 \%$ & 810 & $100 \%$ & 332 & $100 \%$ & 478 & .608 \\
\hline 0 & $2.5 \%$ & 20 & $3.3 \%$ & 11 & $1.9 \%$ & 9 & \\
\hline 1 & $79.6 \%$ & 645 & $79.8 \%$ & 265 & $79.5 \%$ & 380 & \\
\hline 2 & $13.8 \%$ & 112 & $13.6 \%$ & 45 & $14.0 \%$ & 67 & \\
\hline 3 & $2.7 \%$ & 22 & $2.4 \%$ & 8 & $2.9 \%$ & 14 & \\
\hline 4 or more & $1.4 \%$ & 11 & $0.9 \%$ & 3 & $1.7 \%$ & 8 & \\
\hline
\end{tabular}




\begin{tabular}{|l|l|l|l|l|l|l|l|}
\hline & All respondents & $N$ & Primary Care & $n$ & Specialty Care & $n$ & $\begin{array}{l}p \text { - } \\
\text { value }\end{array}$ \\
\hline Years in practice & & & & & & & .110 \\
\hline Less than 1 year & $5.3 \%$ & 43 & $6.6 \%$ & 22 & $4.4 \%$ & 21 & \\
\hline $1-2$ years & $7.5 \%$ & 61 & $7.5 \%$ & 25 & $7.5 \%$ & 36 & \\
\hline $2-5$ years & $17.8 \%$ & 144 & $14.5 \%$ & 48 & $20.1 \%$ & 96 & \\
\hline $5-10$ years & $17.9 \%$ & 145 & $18.7 \%$ & 62 & $17.4 \%$ & 83 & \\
\hline $10-15$ years & $18.4 \%$ & 149 & $16.3 \%$ & 54 & $19.9 \%$ & 95 & \\
\hline More than 15 years & $33.0 \%$ & 267 & $36.4 \%$ & 121 & $30.6 \%$ & 146 & \\
\hline
\end{tabular}

\section{Regret Items}

The majority of the primary care group selected "pursue PA school" $(n=254,76.3 \%)$ as did the specialty care group $(n=383$, $78.6 \%)$ when advising someone who was considering the career. There was no statistically significant difference between the primary and specialty care groups, $\chi^{2}(1, N=820)=0.64, p=.42$. When asked if the profession has been worth the sacrifices made, the primary care group $(n=33,10.1 \%)$ indicated similar regret to the specialty care group $(n=34,7.1 \%)$. This result was not statistically significant, $\chi^{2}(1, N=805)=2.19, p=.14$. The primary $(n=91,27.8 \%)$ and specialty care groups $(n=125,26.2 \%)$ reported regret similarly when asked if they would become a PA again if given the choice, $\chi^{2}(1, N=804)=.26, p=.61$. This result was not statistically significant.

\section{Burnout}

Primary care respondents reported higher levels of burnout $(M=2.71, S D \pm 1.19)$ than the specialty care group $(M=2.50, S D \pm$ 1.10). This result is statistically significant $(t(4)=2.38, p=.02)$ between the groups reflecting higher perceived burnout among the primary care group.

\section{Work/Life Balance}

Statistical significance was found regarding work/ life balance with the primary care group scoring this item lower $(M=3.94, S D \pm$ 1.14) than the specialty care group $(M=4.16, S D \pm 0.99)$ indicating those in primary care have a less sustainable work/life balance than those practicing in specialty care, $t(4)=-2.97, p=.003$.

Salary: There was a statistically significant difference in salary between the two groups with higher compensation for specialty care, $\chi^{2}(7, N=740)=33.46, p<.001$. See Figure 1 for salary range and results by group.

Work Schedules: The two groups had similar control over their hours worked, $\chi^{2}(5, N=820)=8.02, p=.15$, and control over their schedule, $t(4)=.38, p=.69$. Neither of these categories were statistically significant. The two groups scored the degree of schedule control nearly identical $\left(M_{\text {specialty }}=3.26, S D_{\text {specialty }} \pm 1.10 ; M_{\text {primary }}=3.29, S D_{\text {primary }} \pm 1.07\right)$. When asked about work hours the primary care group $(n=146,43.8 \%)$ and specialty care group $(n=218,44.8 \%)$ predominantly worked 40 to 49 hours per week. See Figure 2 for the hours per week worked distribution between the two groups.

Career Satisfaction: The groups were similar in their reporting of career satisfaction and differences were not statistically significant. The specialty care group mean was $4.39(S D \pm .87)$ while the primary care group mean was $4.27,(S D \pm .99), t(4)=$ $1.78, p=.07$.

Additional Factors: Statistical significance was not found with the number of jobs worked in which participants were employed as a PA, $\chi^{2}(4, N=828)=1.99, p=.74$, number of children, $\chi^{2}(5, N=827)=3.11, p=.68$, debt upon graduation from PA school, $\chi^{2}$ $(7, N=819)=6.61, p=.47$, or relationship status, $\chi^{2}(4, N=826)=5.42, p=.14$. See Figure 3 for visualization of student loan debt by primary and specialty care groups. 
40

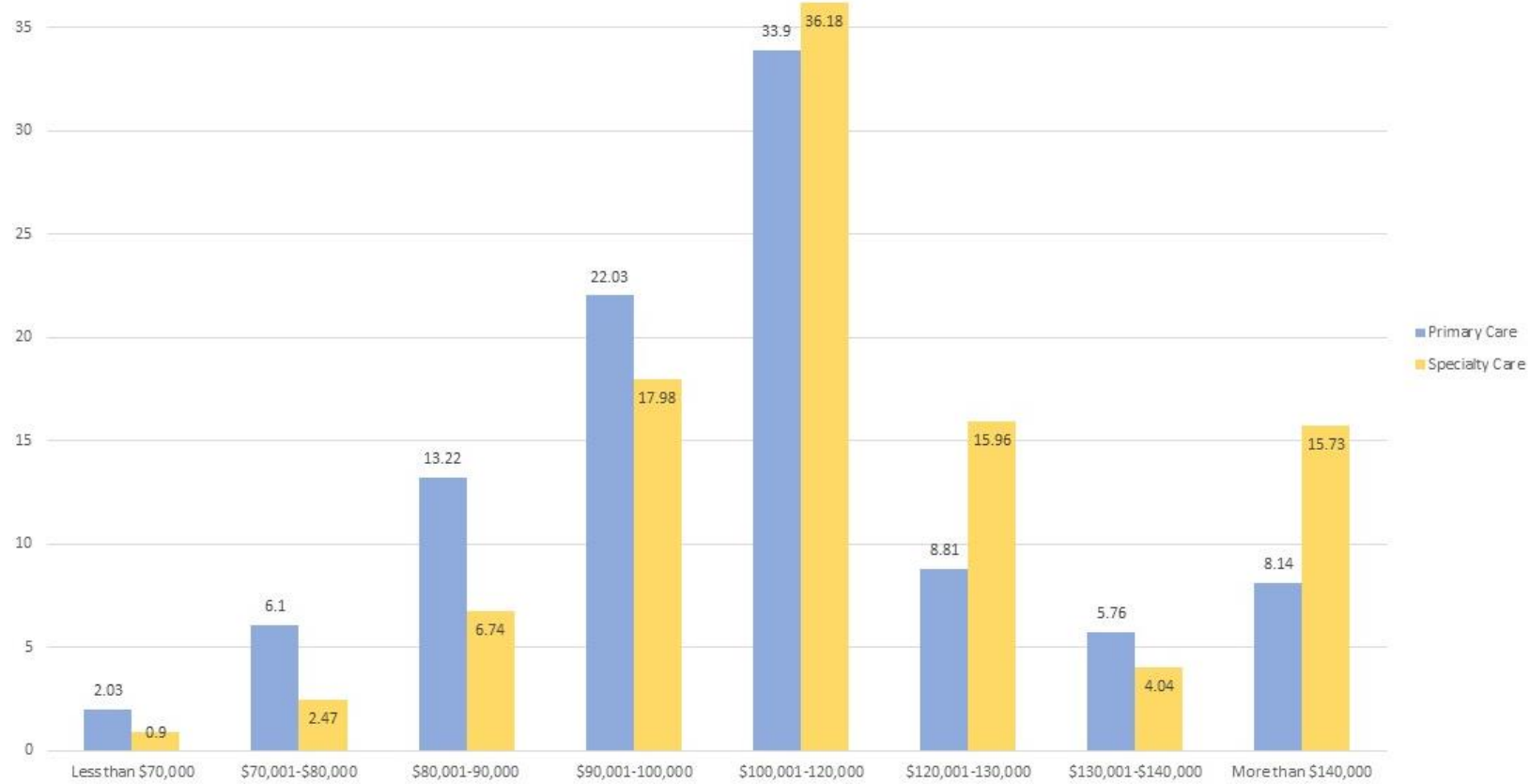

Figure 1. Primary care and specialty care reported yearly gross income

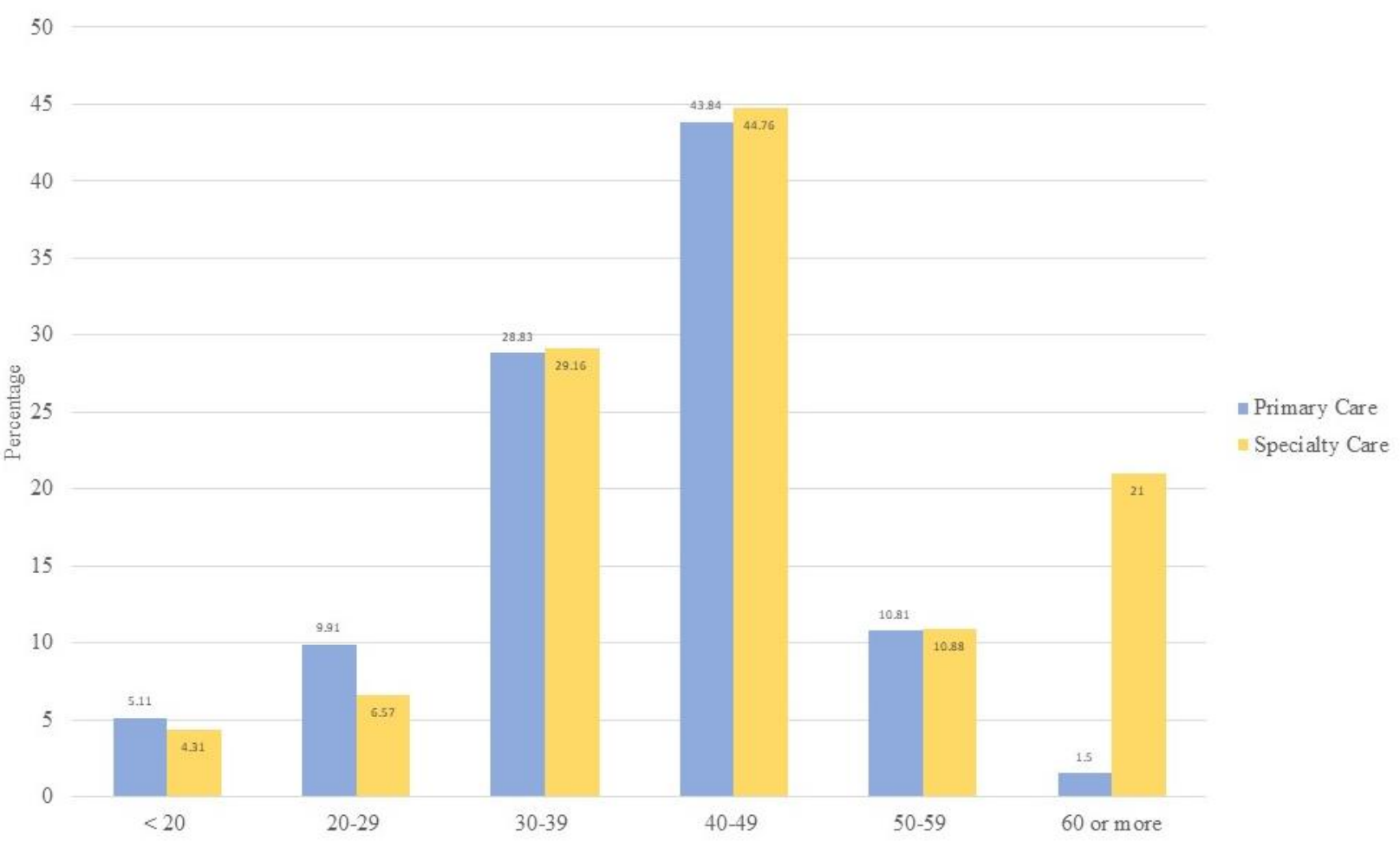

Figure 2. Number of weekly hours worked per week by percentage of respondents in primary and specialty care 


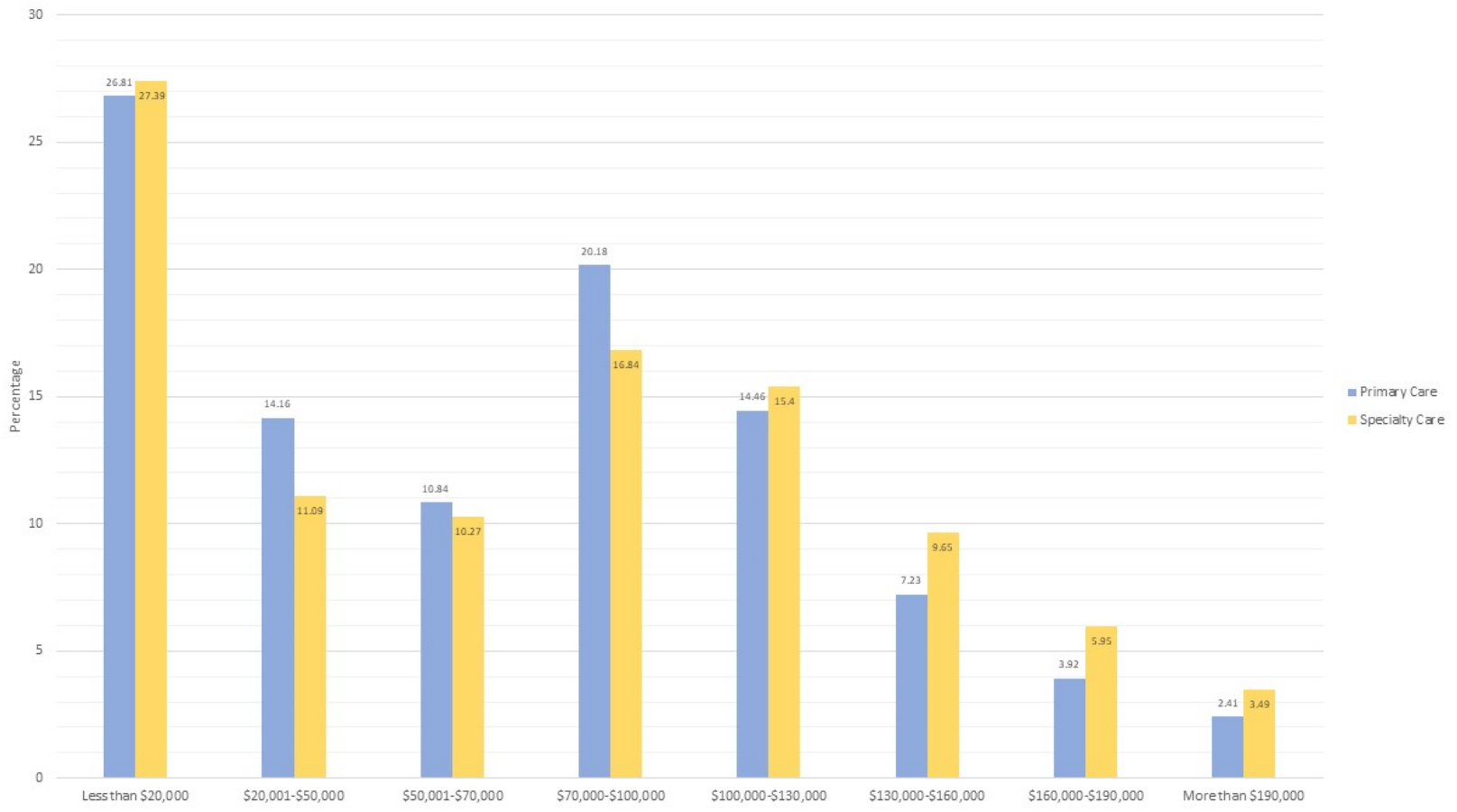

Figure 3. Student load debt by primary and specialty care groups

Decision Regret Scale: The Decision Regret Scale demonstrated good reliability with Cronbach alpha $=.89 .{ }^{11}$ The five-item Decision Regret Scale can be found in Figure $4 .{ }^{11}$ Analysis of the regret items indicated our sample displayed good reliability and concurrent validity. The correlations between the published Decision Regret Scale and all three regret items were highly statistically significant with the question of, "If you could choose again, would you choose to become a PA or choose a different career path?" being the highest correlated $(r(790)=.74, p<.001) .{ }^{11}$ Correlations were similar between the regret items asking how respondents would advise someone considering a career as a PA $(r(794)=.65, p<.001)$ and if they feel their profession has been worth the sacrifices made $(r(791)=.63, p<.001)$.

Satisfaction with Decision Scale: The Satisfaction with Decision Scale also demonstrated good reliability with Cronbach alpha $=.86 .{ }^{10}$ The six-item Satisfaction with Decision Scale is displayed in Figure 5.10 When compared to this published scale, the correlation of each regret item was also significant, with the question of, "If you could choose again, would you choose to become a PA or choose a different career path?" being the highest correlated $(r(791)=.63, p<.001) .{ }^{10}$ Correlations on the regret items that asked how respondents would advise someone considering a career as a PA $(r(796)=.59, p<.001)$ and if they feel the profession has been worth the sacrifices made $(r(793)=.58, p<.001)$ were also highly correlated.

Additionally, the Decision Regret Scale and Satisfaction with Decision Scale were highly correlated with one another $(r(793)=.82$, $p<.001$ ), indicating they were measuring the same construct. ${ }^{10,11}$ There were no statistically significant differences between the primary and specialty care groups' responses to the Decision Regret Scale and Satisfaction with Decision Scale. ${ }^{10,11}$

Correlations to Burnout: Perceived burnout correlated highly with the Decision Regret Scale, $r(731)=.545_{\text {regret, }} p<.001$, and Satisfaction with Decision Scale $(r(733)=.536, p<.001) .10,11$ The strength of the correlation indicates that these are different constructs, however the two are highly correlated among practitioners.

Federally Qualified Health Center (FQHC) and Community Health Clinics (CHC): As a subset of the primary care group, 12 respondents indicated that they worked in a $\mathrm{CHC}$ or $\mathrm{FQHC}$ setting. Although the ability to generalize from this data is limited due to the small sample size, exploratory analysis revealed some differences that may warrant further study. $\mathrm{CHC} / \mathrm{FQHC}$ providers answered regret questions differently than the rest of their colleagues in the primary care group. Only $55 \%$ of the $\mathrm{CHC} / \mathrm{FQHC}$ providers reported they would encourage someone to pursue a PA career path compared to $76 \%$ of the primary care group. Only $58 \%$ of $\mathrm{CHC} / \mathrm{FQHC}$ providers would choose to attend PA school again compared to $72 \%$ in the primary care group. They also 
reported lower work/ life balance $\left(M_{F Q H C}=3.17, S D_{F Q H C} \pm 1.28 ; M_{P C}=3.94, S D_{P C} \pm 1.14\right)$, lower career satisfaction $\left(M_{F Q H C}=3.72\right.$, $\left.S D_{F Q H C} \pm 1.35 ; M_{P C}=4.27, S D_{P C} \pm .99\right)$ and higher perceived levels of burnout $\left(M_{F Q H C}=3.27, S D_{F Q H C} \pm 1.35 ; M_{P C}=2.71, S D_{P C}=\right.$ .99).

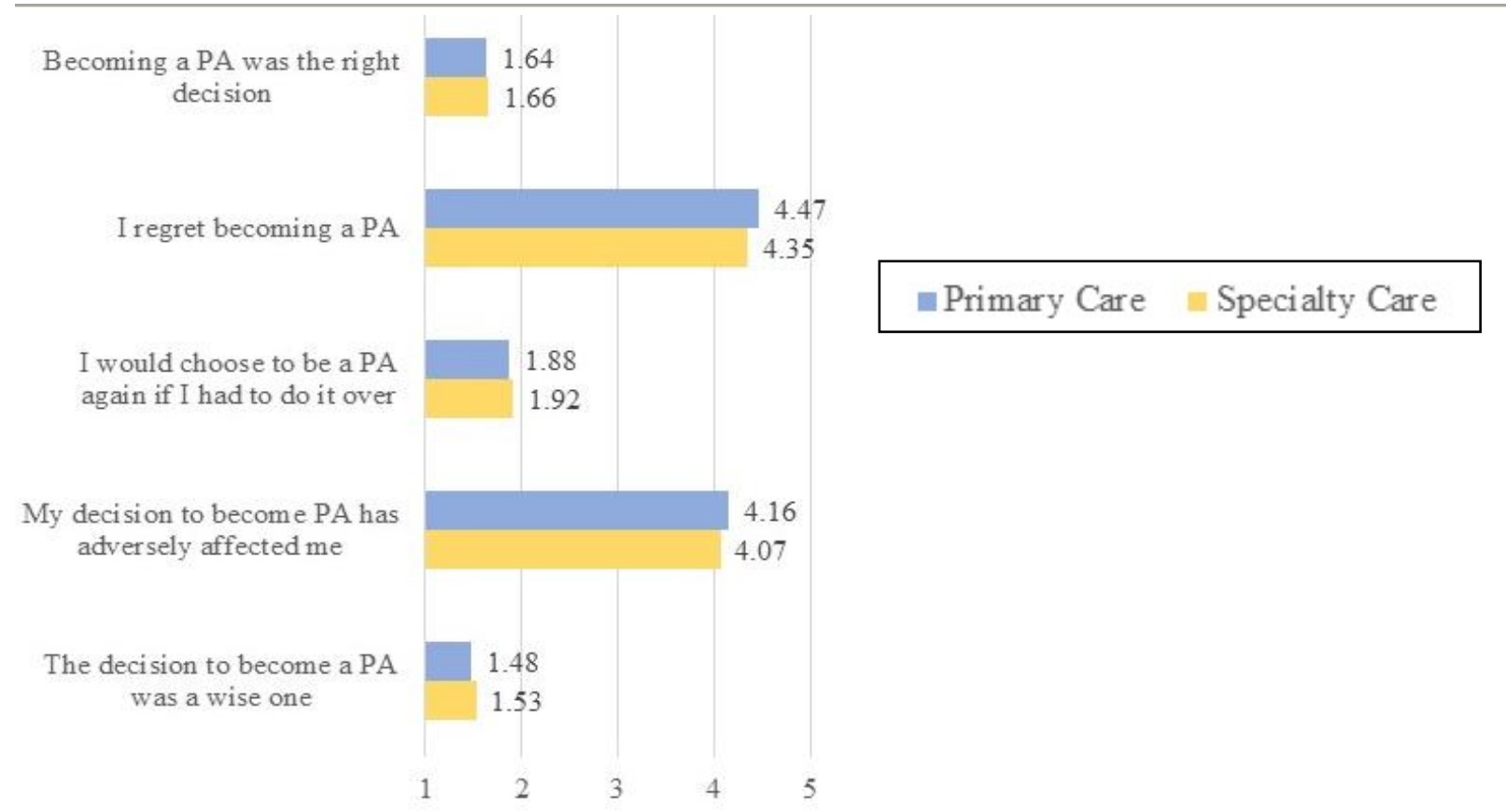

Figure 4. Decision regret mean scores by practice area. Scale anchors are $1+$ strongly agree, $2=$ somewhat agree, $3=$ neither agree nor disagree, 4 = somewhat disagree, 5 = strongly disagree

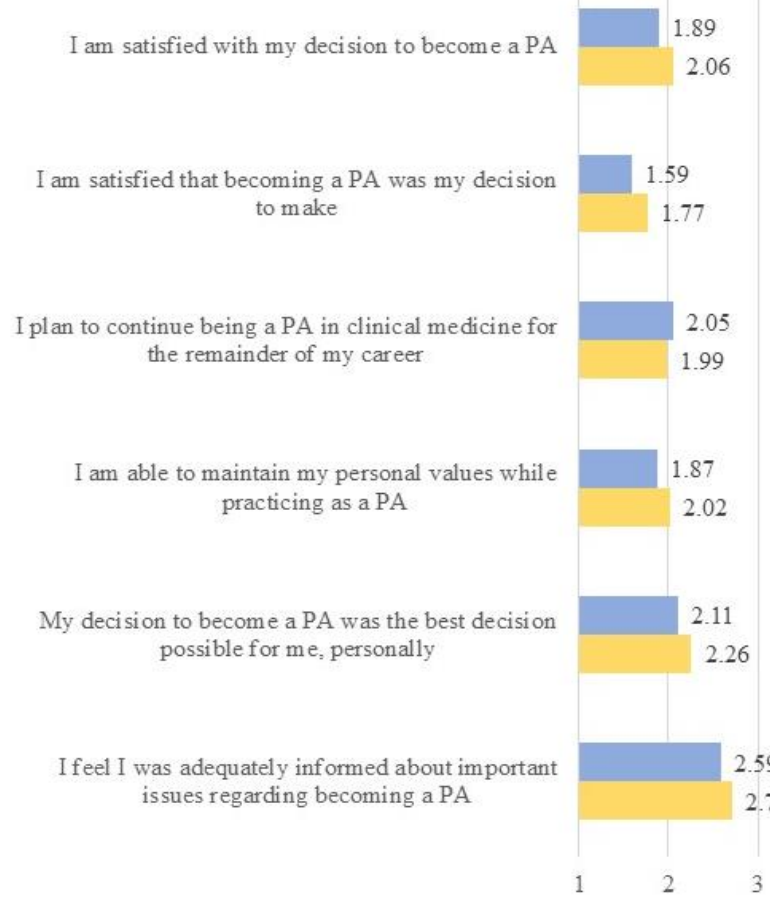

Figure 5. Satisfaction with decision scale mean scores by practice area. Scale anchors are $1+$ strongly agree, $2=$ somewhat agree, 3 = neither agree nor disagree, 4 = somewhat disagree, 5 = strongly disagree
Primary Care 1 Specialty Care 


\section{DISCUSSION}

The results of this research study did not show statistically significant differences in career regret between primary and specialty care groups; however, this finding is significant in that it was unexpected and may give insight to those considering career changes. Statistical significance was found between perceived level of burnout and the sustainability of work-life balance. The primary care group reported higher levels of burnout and a less sustainable work-life balance despite no statistically significant difference in hours worked per week, relationship status, number of children, or control over their schedule. Additionally, the primary care group did not report higher student loan debt burden. The reason for the perceived higher burnout and less sustainable work-life balance remains unclear; however, statistical significance was found in annual gross income, with primary care earning less. One possible explanation could be that the higher pay offsets the burden of work demands since those in specialty care are receiving more monetary compensation than those in primary care. The higher income may lead to a better quality of life or improved lifestyle.

It is worth noting that both primary and specialty care PAs had a low rate of regret on all three regret items. Satisfaction was also rated highly among both groups, which supports other studies that have found a high rate of job satisfaction among PAs. ${ }^{1-3}$ Although the primary care group reported a less sustainable work-life balance, the overall mean was still low.

While all three regret items had a high correlation coefficient, asking respondents if they would choose to become a PA again was the regret item that correlated most highly with previously validated Decision Regret and Satisfaction with Decision Scales indicating it is the best single question determinant of regret of the three regret items. ${ }^{10,11}$

Perceived burnout correlated highly with the Decision Regret and Satisfaction with Decision Scales. ${ }^{10,11}$ Primary care PAs showed statistically significant higher perceived levels of burnout; however, there was no statistically significant difference in regret between the primary and specialty care groups. The correlation value indicates that although these items were highly correlated, they were measuring different constructs, meaning regret and burnout are not the same and suggests that burnout likely occurs prior to career regret. Future research may continue to focus on studying these constructs separately.

The small sample size of those working in $\mathrm{FQHC} / \mathrm{CHC}$ settings prohibited statistical analysis with the larger primary care group; however, the sampling from the $\mathrm{FQHC} / \mathrm{CHC}$ group appears to have a perspective that differs from those who are not practicing in this same setting. Future research may focus specifically on this population to determine if career regret is higher in these settings. Future research may also evaluate the effect salary has on burnout and the sustainability of work-life balance or if other benefits, such as paid leave or insurance and retirement packages, play a role.

\section{Limitations}

Limitations of this study include the low response rate despite incentives for participation; however, the physical number of respondents is high and consists of a randomized sample of PAs from across the United States. Another limitation of this study includes using ranges rather than exact numbers for salary, hours per week worked, and student loan debt. Future research should consider allowing participants to enter exact numbers in order to calculate a mean in these areas. Although the email rental list from AAPA did not include geriatric and pediatric specialties, participants were able to enter these fields into the survey and were therefore classified into the primary care group. Future research may focus further on career regret with regard to years of practice, how frequently respondents had changed from working in primary care to specialty care or vice versa, and further exploring the impact on student loan debt with regard to career regret. For example, determining the length of time it took to pay off student loan debt, what area of medicine respondents practiced in when the debt was paid off, and if respondents switched to a primary care or specialty position in order to have a better quality of life once student loan debts were paid.

\section{CONCLUSION}

There is no statistically significant difference in career regret between primary care and specialty care PAs. Reported regret among all respondents was low, suggesting that PAs are generally satisfied with their career choice, and an optimistic choice for prospective PAs remains regardless of the field they enter; however primary care PAs reported higher rates of perceived burnout and a less sustainable work-life balance than those practicing in specialty care. PAs practicing in specialty care reported higher annual gross incomes. This study did not find statistically significant differences between the two groups in regard to career satisfaction, hours worked per week, and control over schedule. PAs who are considering changing specialties and new graduates entering the field may find this information helpful when deciding which area of medicine in which to practice. Changing from primary care to specialty care or vice versa may not lead to less career regret. Career regret and burnout were found to be different constructs with further investigation needed in how the two are related and the impact salary has on burnout and employment sustainability.

(C) The Internet Journal of Allied Health Sciences and Practice, 2019 


\section{REFERENCES}

1. Hooker RS, Kuilman L, Everett CM. Physician assistant job satisfaction: a narrative review of empirical research. JPAE. 2015;26:176-86. [PMID: 26599310]

2. Marvelle K, Kraditor K. Do PAs in clinical practice find their work satisfying? JAAPA. 1999; 12:43-50. [PMID: 10747644]

3. Job Satisfaction. Clinician Reviews. 2017;27:25-30.

4. Lemkau J, Rafferty J, Gordon R. Burnout and career-choice regret among family practice physicians in early practice. AAFP. 1994;145:213-22. [PMID: 7976472]

5. Halbesleben JRB, Rathert C. Linking physician burnout and outcomes: exploring the dyadic relationship between physicians and patients. Health Care Manage Rev. 2008;33:29-39. [PMID: 18091442]

6. Fine K. How can physicians combat industry shortages and meet patient demands. Medical Economics. November 8 , 2017. Available at: http://medicaleconomics.modernmedicine.com/medical-economics/news/how-can-physicianscombat-industry-shortages-and-meet-patient-demands. Accessed January 5, 2018.

7. Hoff T. Understanding U.S. physician satisfaction: state of the evidence and future directions. $J$ Healthc Manag. 2015;60:409-28. [PMID: 26720985]

8. Phillips J. The impact of debt on young family physicians: unanswered questions with critical implications. J Am Board Fam Med. 2016;29:177-9. [PMID: 26957372]

9. Department of Health and Human Services. Centers for Medicare and Medicaid Services. CMS Manual System: Medicare Claims Processing. March 3, 2011. Available at: https://www.cms.gov/Regulations-and-

Guidance/Guidance/Transmittals/downloads/R2169CP.pdf. December 11, 2017.

10. Holmes-Rovner M, Kroll J, Schmitt N, Rovner DR, Breer ML, et al. Patient satisfaction with health care decisions: the satisfaction with decision scale. Med Decis Making. 1996;16:56-64.

11. Brehaut JC, O'Connor AM, Wood TH, Hack TF, Siminoff L, et al. Validation of a decision regret scale. Med Decis Making. 2003;23:281-92. 